\title{
Silencing Formin-like 2 inhibits growth and metastasis of gastric cancer cells through suppressing internalization of integrins
}

\author{
Banghua Zhong, Kewei Wang, Hao Xu and Fanmin Kong ${ }^{*}$ (i)
}

\begin{abstract}
Background: Formin-like 2 (FMNL2) is a member of Formin family which governs cytokinesis, cellular polarity and morphogenesis. Dysregulation of FMNL2 has been discovered in cancers and is closely related to cancers. However, the role of FMNL2 in gastric cancer remains unclear. In this study, we aimed to investigate the role of FMNL2 in gastric cancer cells.

Methods: A FMNL2-specific shRNA was employed to decrease the endogenous expression of FMNL2. Then the degree of proliferation, apoptosis, migration and invasion of gastric cancer cells was assessed by MTT assay, flow cytometry, wound healing assay and transwell assay, respectively. The expression and distribution of FMNL2 and protein kinase C (PKC) a was detected by immunofluorescence. The internalization of integrins was detected by enzymelinked immunosorbent assay.
\end{abstract}

Results: Our results showed that silencing FMNL2 suppressed proliferation, migration and invasion, and induced apoptosis of gastric cancer cells. The integrin internalization induced by PKC was declined by FMNL2 silencing.

Conclusions: Our study reveals that silencing FMNL2 suppresses growth and metastasis of gastric cancer cells. Modulation on integrin internalization may be implicated in the role of FMNL2 in growth and migration of gastric cancer cells. Our study indicates that FMNL2 may become a potential therapeutic target for gastric cancer.

Keywords: Apoptosis, Formin-like 2, Gastric cancer, Integrin internalization, Invasion, Migration, Proliferation

\section{Background}

Gastric cancer, which threatens human health, is the fifth most common cancer worldwide with approximately one million cases in 2012 [1]. Surgery is the curative modality for gastric cancer treatment. However, the recurrence rate is still high, and the 5-year survival rate is low [2].

Integrins are a group of $\alpha \beta$ heterodimers. Integrins are parts of the major receptors spanning through the lipid bilayer of cells. Integrins bind directly to extracellular matrix components, transduce signals outside-in and activate intracellular signals in context of cytokine receptors or growth factor receptors. Internalization

*Correspondence: fanminkong@126.com

Department of Gastric, Intestine and Hernia Surgery, The First Affiliated

Hospital of China Medical University, Shenyang 110001, People's Republic of China and recycling of integrins emerges as a major player in controlling integrin action [3]. Integrins also contribute to tumor progression and are implicated in cell survival, metastasis, angiogenesis and drug resistance [4-8]. They also influence the response of host cells to cancers [8]. Integrins are regarded as appealing targets for tumor therapy [8].

Formins are a group of Rho guanosine triphosphatase (GTPase) effectors, governing cytokinesis, polarity, adhesion and morphogenesis [9]. Diaphanous-related Formins (DRFs) are a conserved subgroup of Formins. They are involved in a wide range of cellular processes, including filopodium formation, cell migration and cell polarity [9$11]$, and contribute to many physiological or pathological processes [12-14]. Formin-like 2 (FMNL2), a member of DRFs, locates on chromosome 2q23.3. FMNL2 contains a GTPase-binding domain and an autoregulatory domain 
[15], and acts as both a downstream effector and an upstream modulator of Rho family GTPases [11]. FMNL2 plays a key role in actin filament nucleation or elongation which influences cell morphology [9]. FMNL2 also has a close relationship with cancer. For example, FMNL2 enhances the growth and metastasis of colon cancer in which FMNL2 is highly expressed [16-18]. Moreover, FMNL2 performs an inhibitory effect on motility of hepatocarcinoma which shows a lower FMNL2 level than normal livers [19]. In addition, patients with aberrant FMNL2 expression show a lower 5-year survival rate [19]. Dysregulation of FMNL2 has been discovered in several types of cancers and is associated with the development of aggressive tumors [16-20]. However, the role of FMNL2 in gastric cancer remains unclear.

In the present study, we aimed to investigate the effect of FMNL2 silencing on gastric cancer cells. The results of our study indicate that FMNL2 may act as an oncogene in gastric cancer cells and has the potential to become a therapeutic target for gastric cancer.

\section{Materials asnd methods \\ Cells}

Gastric cancer cell lines BGC-823, MGC-803, HGC27 were obtained from Zhongqiaoxinzhou Biotechnology Co., Ltd (Shanghai, China). SGC-7901 cell line was obtained from CHI Scientific (Jiangyin, China). BGC-823 and MGC-803 cells were grown in Dulbecco's Modified Eagle's Medium (Gibco, Grand Island, NY, USA) with $10 \%$ fetal bovine serum (FBS; Hyclone, Logan, UT, USA). SGC-7901 and HGC-27 cells were grown in RPMI 1640 medium (Gibco) with $10 \%$ FBS. All these cells were cultured in a humid atmosphere at $37^{\circ} \mathrm{C}$ with $5 \% \mathrm{CO}_{2}$.

\section{Transfection}

HGC-27 cells were seeded in a 6-well plate $\left(2 \times 10^{5}\right.$ cells/ well) and cultured in a cell incubator. Twenty-four hours later, the cells were transfected with FMNL2 shRNA (target sequence: $5^{\prime}$-GTGGTAGCAGGTAACTCTG-3') or negative control using Lipofectamin 2000 Reagent (Invitrogen, Carlsbad, CA, USA) according to the manufacturer's protocol. Then the cells were maintained in cell

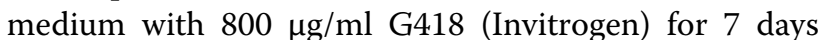
to select stably transfected cells. Cells stably transfected with FMNL2 shRNA were named as FMNL2 silencing. Cells stably transfected with negative control were named as negative control. Cells without transfection were named as cells only.

\section{Quantitative real-time PCR (qRT-PCR)}

Total RNA in cells from each group was extracted using a High-purity Total RNA Fast Extraction kit (BioTeke, Beijing, China) and reverse transcribed to cDNA using
Oligo $(\mathrm{dT})_{15}$ and Super M-MLV Reverse Transcriptase (BioTeke) according to the manufacturers' instructions. mRNA level of FMNL2 in each group was measured by qRT-PCR (SYBR Green method) with cDNA as the template. The following primers were used: forward primer for FMNL2, 5'-CCCGCTCTGGAAGACATT-3'; reverse primer for FMNL2, 5'-CTGCCAACAGTTCTAAGA CAAG- ${ }^{\prime}$; forward primer for $\beta$-actin, $5^{\prime}$-CTTAGTTGC GTTACACCCTTTCTTG-3'; reverse primer for $\beta$-actin, 5'-CTGTCACCTTCACCGTTCCAGTTT-3'. SYBR Green Reagent was obtained from Solarbio (Beijing, China). The relative mRNA level of FMNL2 was normalized to $\beta$-actin and calculated using $2^{-\Delta \Delta C t}$ method.

\section{Western blot}

Proteins in each group were extracted using radio immunoprecipitation assay lysis buffer (Beyotime Biotechnology, Haimen, China) containing $1 \%$ phenylmethanesulfonyl fluoride (Beyotime Biotechnology). The concentration of proteins in each group was measured using a BCA Protein Assay Kit (Beyotime Biotechnology). Forth microgramme proteins in each group were separated by sodium dodecyl sulfate polyacrylamide gel electrophoresis. After electrophoresis, the proteins were transferred onto polyvinylidene fluoride membranes (Millipore, Bedford, MA, USA). The membranes were blocked with $5 \%$ skim milk, followed by incubating with primary antibodies against FMNL2 (1:500; Novus, Oakville, ON, Canada), E-cadherin (1:2000, Proteintech, Wuhan, China), Vimentin (1:2000, Proteintech), $\mathrm{N}$-cadherin (1:2000, Proteintech) or $\beta$-actin (1:500; Bioss, Beijing, China) at $4{ }^{\circ} \mathrm{C}$ overnight. After rinsing in Tris buffered saline with Tween (TBST), the membranes were incubated with horseradish peroxidase (HRP)-conjugated goat-anti-rabbit $\operatorname{IgG}(\mathrm{H}+\mathrm{L})$ or HRP-conjugated goat-anti-mouse $\operatorname{IgG}(\mathrm{H}+\mathrm{L})$ (1:5000; Beyotime Biotechnology) at $37{ }^{\circ} \mathrm{C}$ for $45 \mathrm{~min}$. After rinsing in TBST, the targeted bands were visualized using an ECL Kit (Beyotime Biotechnology).

\section{3-(4,5-Dimethyl-2-thiazolyl)-2,5-diphenyl-2-H-tetrazolium bromide (MTT) assay}

Cells in each group were seeded into 96-well plates $\left(4 \times 10^{3}\right.$ cells/well $)$ and cultured in a cell incubator for 0, 24, 48 and $72 \mathrm{~h}$, respectively. Then MTT (Sigma, St. Louis, MO, USA) at a final concentration of $0.5 \mathrm{mg} /$ $\mathrm{ml}$ was added into each well. After incubating for additional $4 \mathrm{~h}, 150 \mu \mathrm{l}$ dimethyl sulfoxide (DMSO, Sigma) was added into each well to dissolve the crystals after removal of supernate. Thereafter, the absorbance at $490 \mathrm{~nm}$ was measured with a microplate reader (BIOTEK, Winooski, VT, USA). 


\section{Flow cytometry}

Degree of apoptosis in each group was analyzed by flow cytometry with a Cell Apoptosis Detection Kit (KeyGen, Nanjing, China). Cells in each group were collected, rinsed in phosphate buffered saline (PBS) and resuspended in $500 \mu \mathrm{l}$ binding buffer. Then $5 \mu \mathrm{l}$ AnnexinFluorescein Isothiocyanate (FITC) and $5 \mu$ Propidium Iodide (PI) were added into cells for incubation for additional $15 \mathrm{~min}$ at room temperature in dark. The cells were then analyzed with a flow cytometer (BD, Franklin Lakes, NJ, USA).

\section{Wound healing assay}

Cells in each group were seeded into a 6-well plate. When the confluence reached $90 \%$, the cell medium was changed to fresh serum-free medium. Then the cells were treated with mitomycin C ( $1 \mu \mathrm{g} / \mathrm{ml}$; Sigma) for $1 \mathrm{~h}$. Thereafter, scratches were made on single-cell surface with $200 \mu$ l pipette tips. The cells were washed with serum-free medium to remove cell debris, and allowed to migrate for $24 \mathrm{~h}$ in serum-free medium. Images of cells were captured with a microscope at $0 \mathrm{~h}$ and $24 \mathrm{~h}$. The relative migrate rate was calculated using the following formula: relative migrate rate $=($ distance between gap at $0 \mathrm{~h}$ - distance between gap at $24 \mathrm{~h}$ )/distance between gap at $0 \mathrm{~h} \times 100 \%$.

\section{Transwell assay}

Matrigel (BD) was thawed at $4{ }^{\circ} \mathrm{C}$ and diluted at $1: 3$ with serum-free medium. Transwell inserts (Corning, Tewksbury, MA, USA) were put into a 24-well plate and precoated with $40 \mu \mathrm{l}$ of diluted Matrigel. Cells in each group were digested with trypsin (Sigma) and made into singlecell suspension. $200 \mu \mathrm{l}$ single-cell suspension containing $1 \times 10^{4}$ cells was added into the upper chamber and $800 \mu \mathrm{l}$ of RPMI 1640 medium containing 30\% FBS was added into the lower chamber. The cells were allowed to invade for $24 \mathrm{~h}$. Then the cells were rinsed with PBS, fixed with $4 \%$ paraformaldehyde (Sinopharm, Shanghai, China) at room temperature for $20 \mathrm{~min}$, and stained with $0.5 \%$ crystal violet dye (Amresco, Solon, OH, USA) for $5 \mathrm{~min}$. Images of cells were captured under a microscope at $200 \times$ magnification.

\section{Immunofluorescence assay}

Cells were treated with DMSO or 12-O-tetradecanoylphorbol-13-acetate (TPA; 200 nM; Cell Signaling Technology, Danvers, MA, USA) for $5 \mathrm{~min}$. The cells were rinsed with PBS and permeabilized with $0.1 \%$ TritonX-100. After blocking with goat serum, the cells were incubated with FMNL2 antibody (1: 100; Novus) or protein kinase $\mathrm{C}(\mathrm{PKC}) \alpha$ antibody (1: 50; Proteintech,
Wuhan, China) at $4{ }^{\circ} \mathrm{C}$ overnight. Thereafter, the cells were rinsed with $\mathrm{PBS}$ and incubated $\mathrm{Cy} 3$-conjugated goat-anti-rabbit $\operatorname{IgG}(\mathrm{H}+\mathrm{L})$ or FITC-conjugated goatanti-mouse $\operatorname{IgG}(\mathrm{H}+\mathrm{L})$ (1:200; Beyotime Biotechnology). The cells were then rinsed with PBS and observed under a fluorescence microscope (600×; OLYMPUS, Tokyo, Japan).

\section{Integrin internalization assay}

Cells were labeled with EZ-Link Sulfo-NHS-SS-Biotin $(0.5 \mathrm{mg} / \mathrm{ml}$; Thermo Fisher Scientific, Rockford, IL, USA) on ice for $1 \mathrm{~h}$. Then the cells were treated with DMSO or TPA for $30 \mathrm{~min}$. The cells were kept on ice and rinsed with ice-cold PBS. Biotin residual on cell surface was removed by incubating in Tris buffer containing $20 \mathrm{mM}$ MesNa (Aladdin, Shanghai, China) at $4{ }^{\circ} \mathrm{C}$ for $15 \mathrm{~min}$. Superfluous MesNa was quenched by $20 \mathrm{mM}$ iodoacetamide (Aladdin). Then the cells were collected and lysed in lysis solution (containing $200 \mathrm{mM} \mathrm{NaCl}, 15 \mathrm{mM} \mathrm{NaF}$, $75 \mathrm{mM}$ Tris, $7.5 \mathrm{mM}$ EDTA, $7.5 \mathrm{mM}$ EGTA, $1.5 \mathrm{mM}$ Na3VO4, and $1.5 \%$ TritonX-100). The supernatant was collected by centrifugation at $1500 \times g$ at $4{ }^{\circ} \mathrm{C}$ for $10 \mathrm{~min}$. After measuring the concentration with a BCA Protein Assay Kit, the level of biotinylated integrin was analyzed by enzyme-linked immunosorbent assay (ELISA). Briefly, the ELISA plate was precoated with antibodies against integrin- $\beta 1$ (Proteintech), integrin- $\alpha 2$ (Thermo Fisher Scientific), or integrin- $\alpha 5$ (Proteintech) at $4{ }^{\circ} \mathrm{C}$ overnight, and then blocked with $5 \%$ bovine serum albumin. Equivalent sample from each group was added into each well and incubated at $4{ }^{\circ} \mathrm{C}$ overnight. Streptavidin-conjugated HRP (Beyotime Biotechnology) was added into each well after rinsing and incubated at $4{ }^{\circ} \mathrm{C}$ for $1 \mathrm{~h}$. Thereafter, the plate was rinsed, and OPD Color-Substrate Solution (Sigma) was added into each well for incubation at $37{ }^{\circ} \mathrm{C}$ for $25 \mathrm{~min}$. After adding of stop solution, the absorbance was measured at $492 \mathrm{~nm}$.

\section{Statistical analysis}

All experiments were carried out in triplicate. The results were shown as mean \pm SD. Differences between groups were analyzed with one-way analysis of variance. $\mathrm{p}<0.05$ was considered as significant.

\section{Results}

\section{FMNL2 expression level in gastric cancer cell lines}

To select a gastric cancer cell line for our study, the FMNL2 level in gastric cancer cell lines BGC-823, MGC-803, SGC-7901 and HGC-27 was detected by Western blot. As shown in Fig. 1, the FMNL2 level was $2.64 \pm 0.33$-fold in MGC-803 cells, $3.82 \pm 0.41$-fold in SGC-7901 cells, and 5.96 \pm 0.75 -fold in HGC-27 cells, compared with that in BGC-823 cells. Thus, HGC-27 cell 

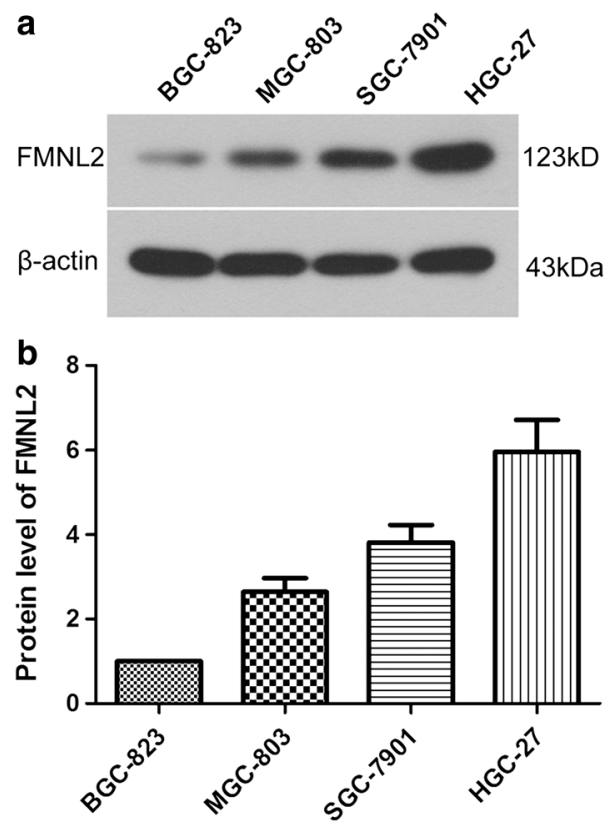

Fig. 1 FMNL2 level in gastric cancer cell lines. a Protein level of FMNL2 in gastric cancer cell lines BGC-823, MGC-803, SGC-7901 and HGC-27 was detected by western blot. $\beta$-Actin served as the internal control. b Relative FMNL2 level in each cell line was calculated. All experiments were repeated three times. The results were shown as mean $\pm S D$

line, with the highest FMNL2 expression, was selected for subsequent experiments.

\section{FMNL2 shRNA decreases the FMNL2 level in HGC-27}

To explore the role of FMNL2 in gastric cancer, a FMNL2-specific shRNA was employed in our study. Then the efficiency of FMNL2 shRNA was verified by qRT-PCR and western blot. After transfection with FMNL2 shRNA, the relative mRNA level of FMNL2 was decreased to $25 \pm 4 \%$ (Fig. 2a), and the relative protein level of FMNL2 was decreased to $22 \pm 4 \%$ (Fig. 2b, c). These results demonstrate that FMNL2 shRNA declines FMNL2level effectively, both at mRNA level and protein level.

\section{FMNL2 silencing inhibits proliferation and induces apoptosis of HGC-27 cells}

After silencing FMNL2, proliferation of HGC-27 cells was assessed by MTT assay. As shown in Fig. 3a, the growth of FMNL2 silencing cells was much slower than that of negative control cells (Fig. 3a). These results demonstrate that FMNL2 silencing inhibits proliferation of HGC-27 cells.
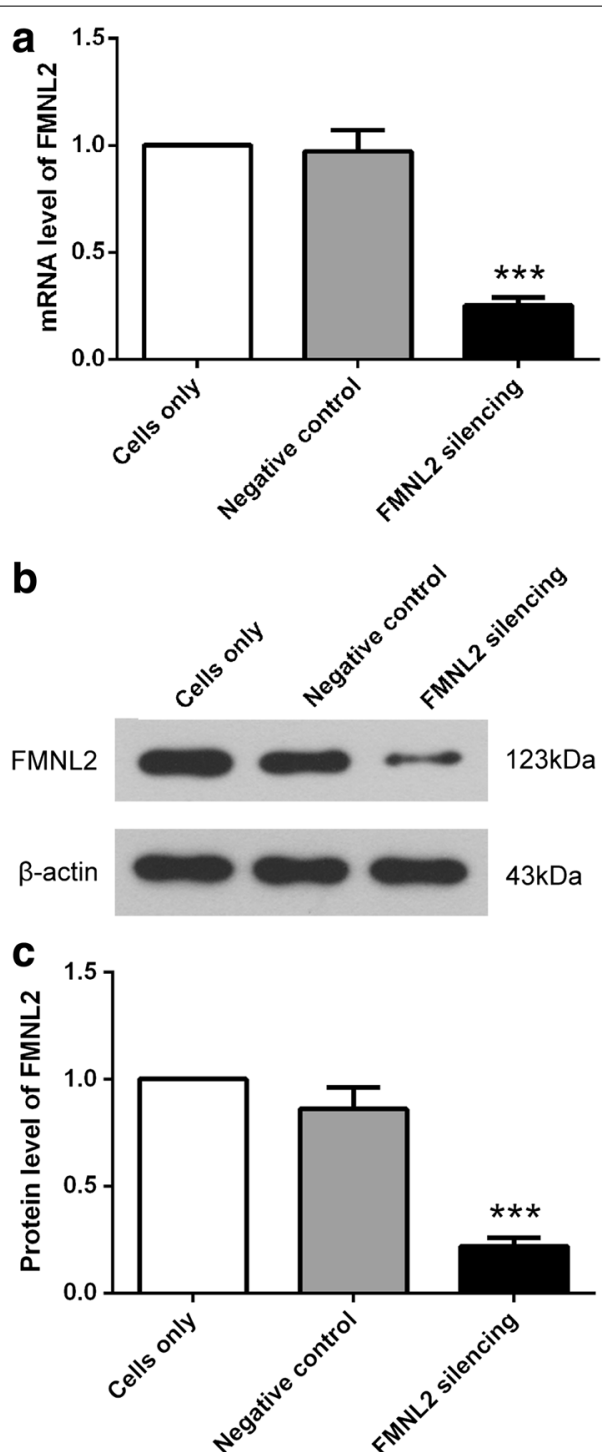

Fig. 2 FMNL2 shRNA decreases FMNL2 level in HGC-27 cells. a mRNA level of FMNL2 in HGC-27 cells was measured by quantitative real-time PCR after FMNL2 silencing. MRNA level of FMNL2 was normalized to $\beta$-actin, and relative mRNA level was calculated using $2^{-\Delta \Delta \mathrm{Ct}}$ method. b, $\mathbf{c}$ After FMNL2 silencing, protein level of FMNL2 was assessed by western blot with $\beta$-actin as internal control. Each experiment was repeated three times. The results were shown as mean $\pm S D .{ }^{* *} p<0.001$ compared with negative control cells

Apoptosis plays a crucial role in cell growth. In this study, effect of FMNL2 silencing on apoptosis of HGC27 cells was assessed by flow cytometry. Results of flow cytometry showed that there was no obvious difference between cells only and negative control cells. FMNL2 silencing cells showed a significant increase in the 


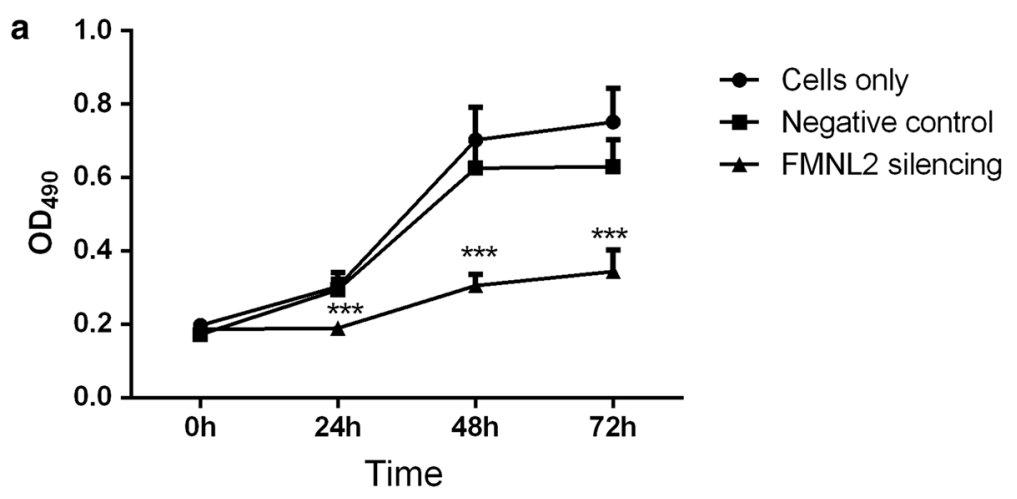

b

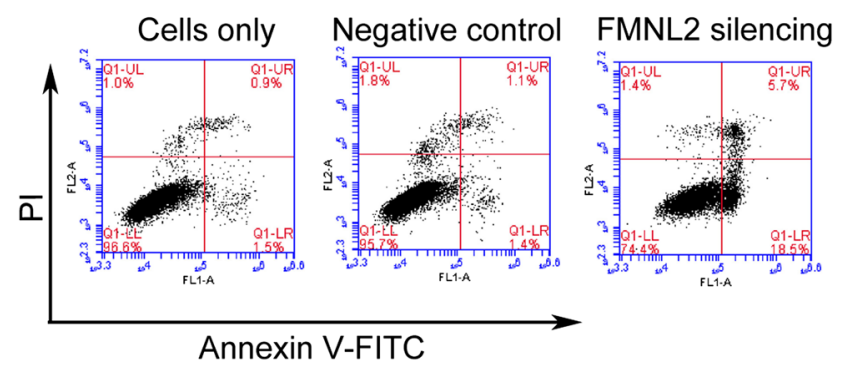

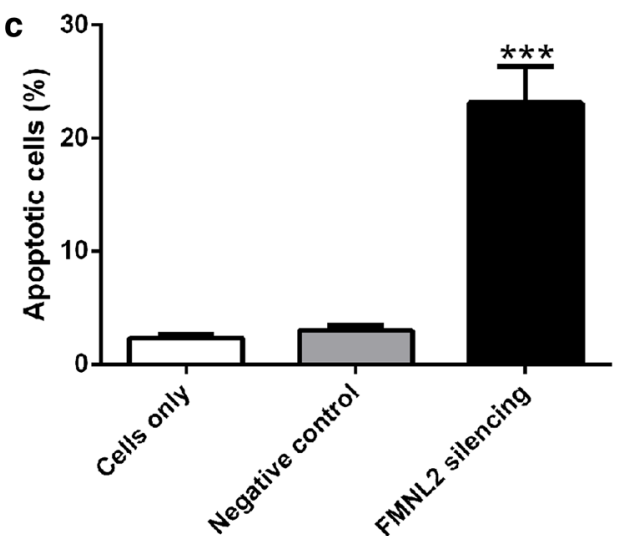

Fig. 3 FMNL2 silencing inhibits growth of HGC-27 cells. a Cell viability of HGC-27 in each group was assessed by MTT assay. b, c After silencing FMNL2, cell apoptosis in each group was detected by flow cytometry. All experiments were performed three times. The results were shown as mean $\pm S D$. ${ }^{* *} p<0.001$ when compared with negative control cells

percentage of apoptotic cells when compared with negative control cells (Fig. 3b, c). These results illustrate that FMNL2 silencing induces apoptosis of HGC-27 cells.

\section{FMNL2 silencing retards migration and invasion of HGC-27} cells

Effect of FMNL2 silencing on migration of gastric cancer cells was evaluated by wound healing assay. Results of our study showed that there was no striking difference between cells only and negative control cells. After silencing FMNL2, the migration rate of FMNL2 silencing cells was $25.45 \pm 1.81 \%$, which was significantly declined compared with negative control cells $(34.84 \pm 0.99 \%)$ (Fig. 4a, b). These results show that silencing FMNL2 suppresses migration of HGC-27 cells.

To explore the effect of FMNL2 silencing on invasion of gastric cancer cells, a transwell assay was carried out. As shown in Fig. 4, negative control cells showed no significant difference when compared with that of cells only. While, the percentage of invasive cells of FMNL2 silencing cells was $40 \pm 6 \%$, which was decreased significantly compared with that of negative control cells $(94 \pm 9 \%)$
(Fig. 4c, d). These results reveal that silencing FMNL2 suppresses invasion of HGC-27 cells.

Also, proteins associated with epithelial-to-mesenchymal transition (EMT) were also assessed by western blot. After silencing FMNL2, the protein level of E-cadherin, which was an epithelial marker, was increased to $2.11 \pm 0.29$-fold (Fig. 5a, b). While the levels of Vimentin and $\mathrm{N}$-cadherin, which were mesenchymal markers, were decreased to $54 \pm 8$ and $41 \pm 6 \%$, respectively (Fig. $5 \mathrm{c}-\mathrm{f}$ ). These results indicate that silencing FMNL2 inhibits EMT of HGC-27 cells.

\section{FMNL2 silencing inhibits integrin internalization induced by PKC}

TPA was employed to activate PKC in our study. Upon TPA treatment, more PKC $\alpha$ was concentrated on plasmalemma compared with cells treated with DMSO, indicating the activation of PKC. Moreover, more FMNL2 was concentrated in cytoplasm upon TPA treatment (Fig. 6).

Additionally, internalization of integrins was also detected in this study. As shown in Fig. 7, activation 

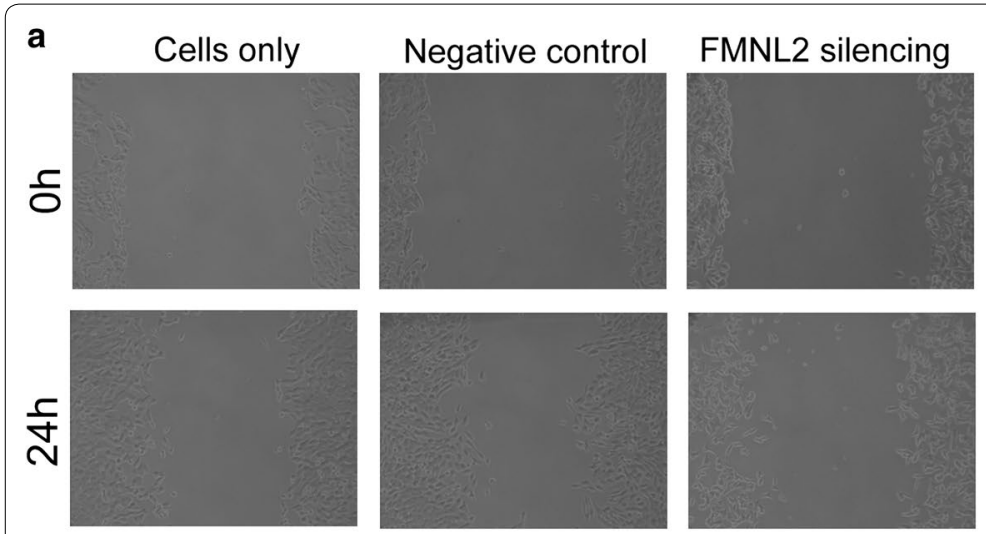

C
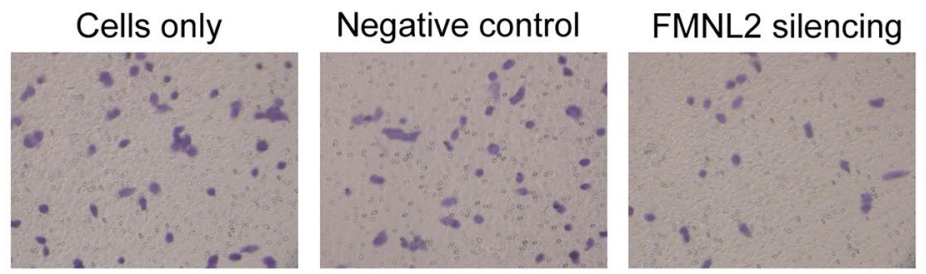
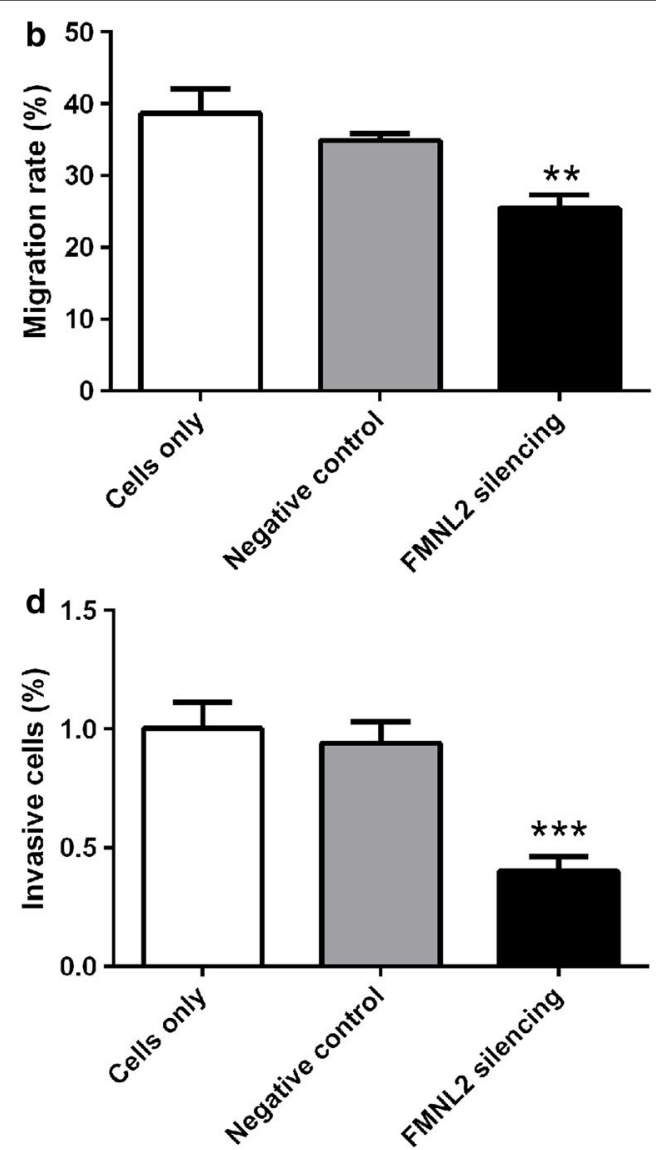

Fig. 4 FMNL2 silencing inhibits migration and invasion of HGC-27 cells. a, b Migration capability of HGC-27 cells in each group was evaluated by wound healing assay. Relative migration rate was calculated. c, $\mathbf{d}$ After silencing FMNL2, invasion capability was assessed by transwell assay. Each experiment was repeated three times. The results were presented as mean $\pm S D$. ${ }^{* *} p<0.01,{ }^{* *} p<0.001$ compared with negative control cells

of PKC by TPA treatment enhanced the internalization of integrin- $\beta 1$, integrin- $\alpha 2$ and integrin- $\alpha 5$. Compared with negative control cells, silencing FMNL2 significantly decreased the internalization of integrin- $\beta 1$, integrin- $\alpha 2$ and integrin- $\alpha 5$. In TPA treated cells, silencing FMNL2 also decreased the PKCinduced internalization of integrin- $\beta 1$, integrin- $\alpha 2$ and integrin- $\alpha 5$. There was no significant difference between FMNL2 silencing + TPA group and cells only+DMSO or negative control+DMSO group. These results demonstrate that silencing FMNL2 reduces $\mathrm{PKC}$-induced internalization of integrins to a nearly normal level.

\section{Discussion}

In the present study, we explored the role of FMNL2 in gastric cancer cells. Silencing FMNL2 suppressed proliferation of gastric cancer cells and induced their apoptosis. FMNL2 silencing also suppressed migration and invasion of gastric cancer cells. Further study showed that internalization of integrins induced by PKC was rescued by FMNL2 silencing. These results of our study indicate that inhibition of integrin internalization may be involved in the effect of FMNL2 silencing on growth and metastasis of gastric cancer cells.

MicroRNAs have close relationships with cancer biology. Clinical trials using microRNA profiling as markers of prognosis and clinical responses were underway [21]. Several microRNAs were reported to suppress growth of colon cancer through targeting FMNL2 [22-24]. Circular RNAs, as emerging biomarkers and targets for cancer [25], recently catch the eyes of researchers. It was reported that circRNA_001569, as a sponge of miR-145, promoted proliferation and invasion of colon cancer through up-regulating FMNL2, which was a functional target of miR-145 [26]. As dysregulation of FMNL2 has been revealed in human cancers and is associated with tumor progression and poor outcomes [19, 20], we speculate that FMNL2 may perform a boosting role in 

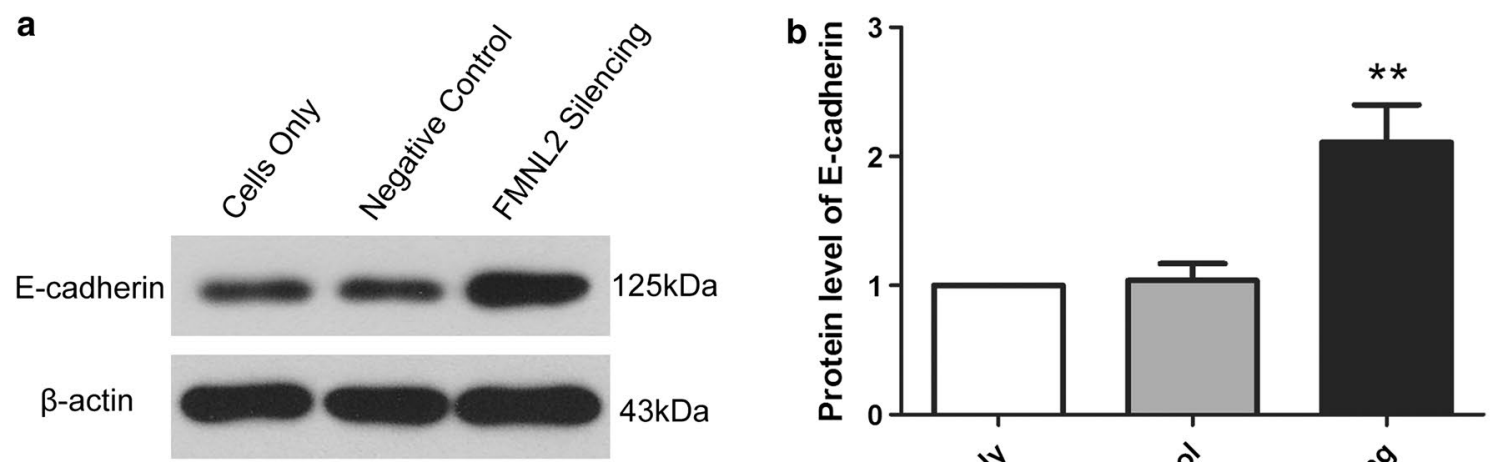

C
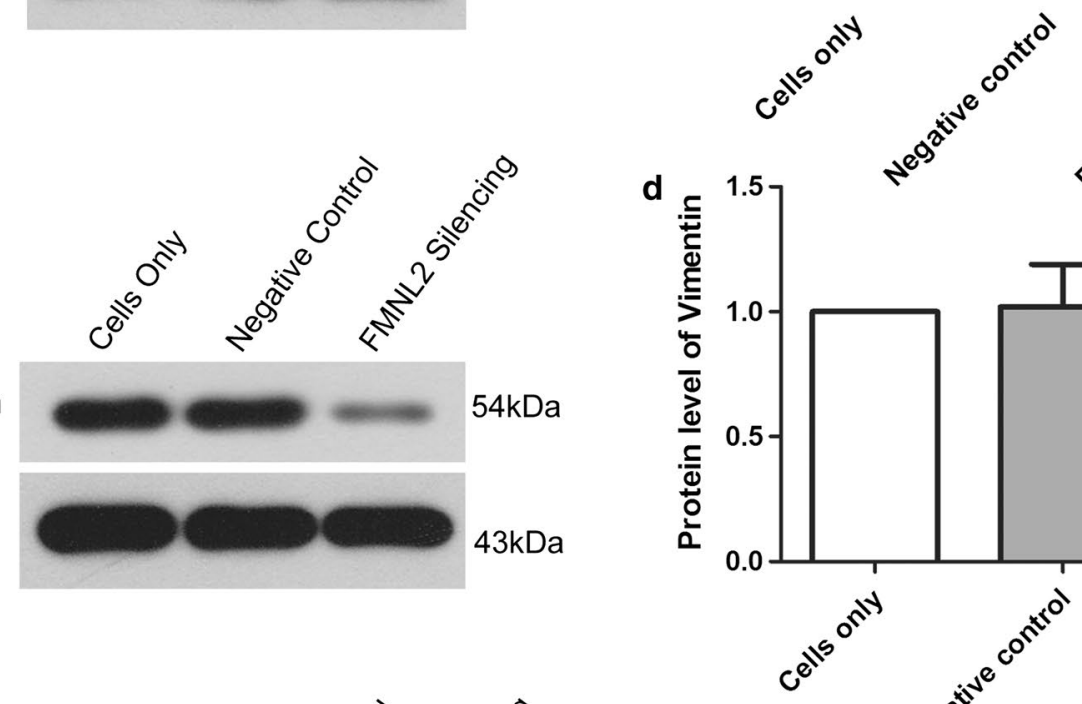

e

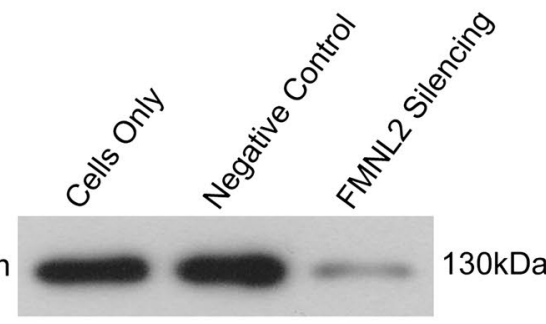

$\mathrm{N}$-cadherin

$\beta$-actin

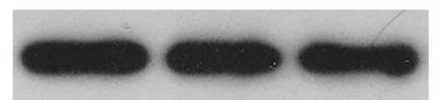

$43 \mathrm{kDa}$

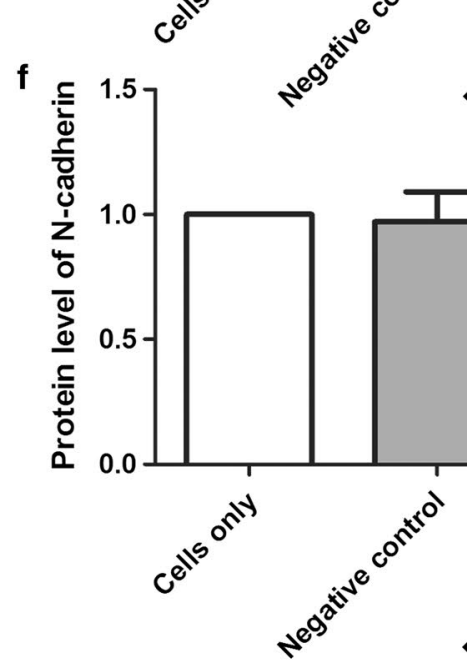

Fig. 5 FMNL2 silencing inhibits epithelial-to-mesenchymal transition of HGC-27 cells. a, b After FMNL2 silencing, protein level of E-cadherin was assessed by western blot. $\beta$-actin served as internal control. $\mathbf{c}$, $\mathbf{d}$ Western blot was performed to detect the protein level of Vimentin with $\beta$-actin as internal control. e, f Protein level of $\mathrm{N}$-cadherin was assessed by western blot after silencing FMNL2. Each experiment was repeated three times. The results were shown as mean $\pm \mathrm{SD} .{ }^{* *} p<0.01,{ }^{* * *} p<0.001$ compared with negative control cells

colon cancer growth based on the above indirect clues. And Zhu et al. show that FMNL2 boosts proliferation of colon cancer cells [18]. To our knowledge, only the report of Zhu et al. [18] showed direct evidence for the role of FMNL2 in cancer cell growth. When it comes to gastric cancer cells, there is no direct or indirect evidence. In our study, FMNL2 silencing suppressed proliferation of gastric cancer cells and induced their apoptosis, indicating that FMNL2 may contribute to gastric cancer growth. As far as we know, our study is the first report 

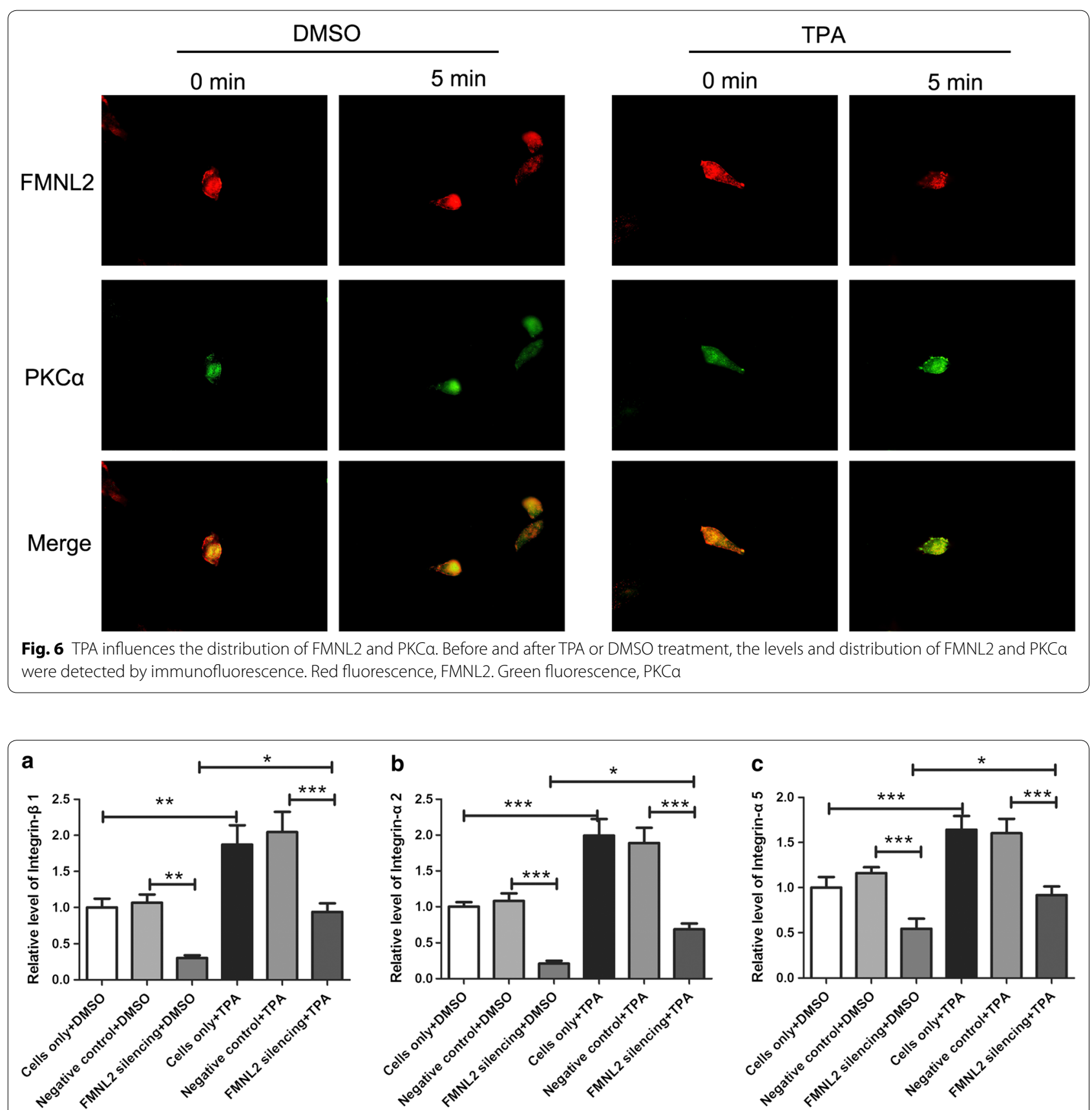

Fig. 7 TPA suppresses internalization of integrins induced by PKC. After treatment with TPA, internalization of integrin- $\beta 1$ (a), integrin-a2 (b) and integrin-a5 (c) was detected. All experiments were repeated three times. The results were presented as mean $\pm S D$. ${ }^{*} p<0.05,{ }^{* *} p<0.01$, ${ }^{* * *} p<0.001$

showing direct evidence for the role of FMNL2 in gastric cancer growth. However, how exactly FMNL2 performs its growth-boosting role in gastric cancer needs to be revealed.

Migration and invasion are crucial initial steps of tumor metastasis. In our study, we also investigated the effect of FMNL2 silencing on migration and invasion of gastric cancer cells. We found that FMNL2 silencing suppressed migration and invasion of gastric cancer cells, indicating that FMNL2 also contributes to metastasis of gastric cancer cells. Consistently, the FMNL2 expression in colon cancer, which has a high FMNL2 level, is correlated with tumor invasion and lymphatic metastasis [16]. FMNL2 is also found to boost invasion and migration of colon cancer [16, 18]. Conversely, in hepatocarcinoma which has a low FMNL2 level, overexpression of FMNL2 
suppresses motility and invasion of hepatocarcinoma cells [19]. Literature research shows that FMNL2 has a close relationship with tumor metastasis. First, FMNL2 is a catalyst for polymerization of linear actin. FMNL2 governs many processes, including cytokinesis, morphogenesis, invasion and migration, depended on remodeling of actin [9]. FMNL2 accumulating at lamellipodia and filopodia tips contributes to actin filament nucleation and elongation, and boosts actin assembly [27, 28]. Second, FMNL2 also modulates EMT which is an important phenomenon contributing to tumor metastasis. The expression of FMNL2 is negatively correlated with epithelial marker E-cadherin and positively correlated with Vimentin. And knockdown FMNL2 leads to EMT, with elevated E-cadherin and declined Vimentin and Snail [17]. Lossing FMNL2 also decreases TGF- $\beta$-induced EMT [17]. In this study, we also confirmed a similar effect of FMNL2 on the protein levels of EMT markers in gastric cancer cells.

The integrin signal has a close relationship with tumor progression, including cell proliferation, migration, invasion and differentiation. Integrins interact with extracellular matrix to provide traction which is required for tumor cell invasion [8]. Integrins also contribute to tumor invasion through regulating matrix metalloproteases (MMPs) which are critical to the proteolysis of matrix proteins $[8,29]$. The ability of cell proliferation is depending on collagenous matrix status [30]. Through regulating MMPs and collagenous matrix status, integrins may also influence tumor cell proliferation. Moreover, integrins are revealed to control the expression of cyclins and cyclin-dependent kinase inhibitors [31,32], which are key regulators of cell cycle progress, thus contributing to cancer cell proliferation. Integrins are also implicated in the process of EMT $[33,34]$, a critical process triggered during tumor metastasis, and contribute to tumor angiogenesis and chemoresistance [30].

Interestingly, integrin trafficking (internalization and recycling) is very important in controlling integrin actions [3]. Tissue factors, such as epidermal growth factor (EGF), platelet-derived growth factor (PDGF) and protein kinase $\mathrm{C}$ ( $\mathrm{PKC})$, have been shown to induce integrin internalization [35-37]. Meanwhile, dysregulation of integrin trafficking is implied in tumorigenesis [38], and integrin internalization is reported to boost cell migration [3]. Due to the important role of integrin internalization, targeting integrin trafficking is regarded as a potential cancer therapy [38]. FMNL2 is required for integrin internalization downstream of PKC. PKC phosphorylates and activates FMNL2, leading to direct binding of FMNL2 to cytoplasmic tails of integrin- $\alpha$ for integrin- $\beta 1$ endocytosis $[3,39]$. Wang et al. also showed that FMNL2 promoted integrin trafficking downstream of PKC [39]. Consistently, in our study, FMNL2 silencing declined integrin internalization induced by $\mathrm{PKC}$ in gastric cancer cells. We speculate that integrin internalization may be implicated in the role of FMNL2 in gastric cancer cells.

\section{Conclusion}

Our study demonstrates for the first time that silencing FMNL2 suppresses proliferation, invasion and migration and induced apoptosis of gastric cancer cells. Additionally, integrin internalization may be implicated in the role of FMNL2 in gastric cancer cells. Our study indicates that FMNL2 may become a potential therapeutic target for gastric cancer.

\begin{abstract}
Abbreviations
FMNL2: Formin-like 2; PKC: protein kinase C; GTPase: guanosine triphosphatase; DRF: diaphanous-related Formin; QRT-PCR: quantitative real-time PCR; TBST: Tris buffered saline with Tween; HRP: horseradish peroxidase; MTT: 3-(4,5-dimethyl-2-thiazolyl)-2,5-diphenyl-2-H-tetrazolium bromide; PBS: phosphate buffered saline; FITC: fluorescein isothiocyanate; PI: propidium iodide; TPA: 12-O-tetradecanoylphorbol-13-acetate; ELISA: enzyme-linked immunosorbent assay; EMT: epithelial-to-mesenchymal transition; MMP: matrix metalloprotease; EGF: epidermal growth factor; PDGF: platelet-derived growth factor.
\end{abstract}

\section{Authors' contributions}

$\mathrm{BZ}$ and FK conceived and designed the study. BZ, KW and HX carried out the experiments and analyzed the data. BZ and FK drafted the manuscript. All authors read and approved the final manuscript.

\section{Acknowledgements}

Not applicable.

\section{Competing interests}

The authors declare that they have no competing interests.

Availability of data and materials

Not applicable.

Content of publication

Not applicable.

Ethics approval and consent to participate

Not applicable.

\section{Funding}

This study was supported by a Grant from the Foundation of Department of Science and Technology, Liaoning Province (No. 2015020512).

\section{Publisher's Note}

Springer Nature remains neutral with regard to jurisdictional claims in published maps and institutional affiliations.

Received: 8 January 2018 Accepted: 26 May 2018

Published online: 01 June 2018

References

1. Torre LA, Siegel RL, Ward EM, Jemal A. Global cancer incidence and mortality rates and trends - an update. Cancer Epidemiol Biomarkers Prev. 2016;25:16-27. 
2. Nashimoto A, Akazawa K, Isobe Y, Miyashiro I, Katai H, Kodera Y, et al. Gastric cancer treated in 2002 in Japan: 2009 annual report of the JGCA nationwide registry. Gastric Cancer. 2013;16:1-27.

3. Paul NR, Jacquemet $G$, Caswell PT. Endocytic trafficking of integrins in cell migration. Curr Biol. 2015;25:R1092-105.

4. Vellon L, Menendez JA, Lupu R. AlphaVbeta3 integrin regulates heregulin (HRG)-induced cell proliferation and survival in breast cancer. Oncogene. 2005;24:3759-73.

5. Ganguly KK, Pal S, Moulik S, Chatterjee A. Integrins and metastasis. Cell Adhes Migrat. 2013;7:251-61.

6. Avraamides CJ, Garmy-Susini B, Varner JA. Integrins in angiogenesis and lymphangiogenesis. Nat Rev Cancer. 2008;8:604-17.

7. Reynolds LE, Wyder L, Lively JC, Taverna D, Robinson SD, Huang X, et al. Enhanced pathological angiogenesis in mice lacking beta3 integrin or beta3 and beta5 integrins. Nat Med. 2002;8:27-34.

8. Desgrosellier JS, Cheresh DA. Integrins in cancer: biological implications and therapeutic opportunities. Nat Rev Cancer. 2010;10:9-22.

9. Faix J, Grosse R. Staying in shape with Formins. Dev Cell. 2006;10:693-706.

10. Eisenmann KM, Harris ES, Kitchen SM, Holman HA, Higgs HN, Alberts AS. Dia-interacting protein modulates Formin-mediated actin assembly at the cell cortex. Curr Biol. 2007;17:579-91.

11. Young KG, Copeland JW. Formins in cell signaling. Biochim Biophys Acta. 2010;1803:183-90.

12. Kitzing TM, Sahadevan AS, Brandt DT, Knieling H, Hannemann S, Fackler OT, et al. Positive feedback between Dia1, LARG, and RhoA regulates cell morphology and invasion. Genes Dev. 2007;21:1478-83.

13. DeWard AD, Eisenmann KM, Matheson SF, Alberts AS. The role of Formins in human disease. Biochim Biophys Acta. 2010;1803:226-33.

14. Weise-Cross L, Taylor JM, Mack CP. Inhibition of diaphanous Formin signaling in vivo impairs cardiovascular development and alters smooth muscle cell phenotype. Arterioscler Thromb Vasc Biol. 2015;35:2374-83.

15. Higgs HN. Formin proteins: a domain-based approach. Trends Biochem Sci. 2005;30:342-53

16. Zhu XL, Liang L, Ding YQ. Overexpression of FMNL2 is closely related to metastasis of colorectal cancer. Int J Colorectal Dis. 2008;23:1041-7.

17. Li Y, Zhu X, Zeng Y, Wang J, Zhang X, Ding YQ, et al. FMNL2 enhances invasion of colorectal carcinoma by inducing epithelial-mesenchymal transition. Mol Cancer Res. 2010;8:1579-90.

18. Zhu XL, Zeng YF, Guan J, Li YF, Deng YJ, Bian XW, et al. FMNL2 is a positive regulator of cell motility and metastasis in colorectal carcinoma. J Pathol. 2011;224:377-88.

19. Liang L, Guan J, Zeng Y, Wang J, Li X, Zhang X, et al. Down-regulation of Formin-like 2 predicts poor prognosis in hepatocellular carcinoma. Hum Pathol. 2011:42:1603-12.

20. Gardberg M, Heuser VD, Koskivuo I, Koivisto M, Carpen O. FMNL2/FMNL3 Formins are linked with oncogenic pathways and predict melanoma outcome. J Pathol Clin Res. 2016;2:41-52.

21. Hayes J, Peruzzi PP, Lawler S. MicroRNAs in cancer: biomarkers, functions and therapy. Trends Mol Med. 2014;20:460-9.

22. Li B, Xie Z, Li Z, Chen S. MicroRNA-613 targets FMNL2 and suppresses progression of colorectal cancer. Am J Transl Res. 2016;8:5475-84.
23. Liang L, Li X, Zhang X, Lv Z, He G, Zhao W, et al. MicroRNA-137, an HMGA1 target, suppresses colorectal cancer cell invasion and metastasis in mice by directly targeting FMNL2. Gastroenterology. 2013;144(624-635):e624.

24. Ren XL, He GY, Li XM, Men H, Yi LZ, Lu GF, et al. MicroRNA-206 functions as a tumor suppressor in colorectal cancer by targeting FMNL2. J Cancer Res Clin Oncol. 2016;142:581-92.

25. Zhang Y, Liang W, Zhang P, Chen J, Qian H, Zhang X, et al. Circular RNAs: emerging cancer biomarkers and targets. J Exp Clin Cancer Res. 2017;36:152.

26. Xie H, Ren X, Xin S, Lan X, Lu G, Lin Y, et al. Emerging roles of cirCRNA_001569 targeting miR-145 in the proliferation and invasion of colorectal cancer. Oncotarget. 2016;7:26680-91.

27. Block J, Breitsprecher D, Kuhn S, Winterhoff M, Kage F, Geffers R, et al. FMNL2 drives actin-based protrusion and migration downstream of Cdc42. Curr Biol. 2012;22:1005-12.

28. Zeng Y, Xie H, Qiao Y, Wang J, Zhu X, He G, et al. Formin-like2 regulates Rho/ROCK pathway to promote actin assembly and cell invasion of colorectal cancer. Cancer Sci. 2015:106:1385-93.

29. Shield K, Riley C, Quinn MA, Rice GE, Ackland ML, Ahmed N. Alpha2beta1 integrin affects metastatic potential of ovarian carcinoma spheroids by supporting disaggregation and proteolysis. J Carcinog. 2007;6:11.

30. Naci D, Vuori K, Aoudjit F. Alpha2beta1 integrin in cancer development and chemoresistance. Semin Cancer Biol. 2015;35:145-53.

31. Honore S, Kovacic H, Pichard V, Briand C, Rognoni JB. Alpha2beta1-integrin signaling by itself controls $\mathrm{G} 1 / \mathrm{S}$ transition in a human adenocarcinoma cell line (Caco-2): implication of NADPH oxidase-dependent production of ROS. Exp Cell Res. 2003;285:59-71.

32. Fournier AK, Campbell LE, Castagnino P, Liu WF, Chung BM, Weaver VM, et al. Rac-dependent cyclin D1 gene expression regulated by cadherinand integrin-mediated adhesion. J Cell Sci. 2008;121:226-33.

33. Feldkoren B, Hutchinson R, Rapaport Y, Mahajan A, Margulis V. Integrin signaling potentiates transforming growth factor-beta 1 (TGF-beta1) dependent down-regulation of E-Cadherin expression -important implications for epithelial to mesenchymal transition (EMT) in renal cell carcinoma. Exp Cell Res. 2017;355:57-66.

34. Bates RC. Colorectal cancer progression: integrin alphavbeta6 and the epithelial-mesenchymal transition (EMT). Cell Cycle. 2005;4:1350-2.

35. Ning Y, Buranda T, Hudson LG. Activated epidermal growth factor receptor induces integrin alpha2 internalization via caveolae/raft-dependent endocytic pathway. J Biol Chem. 2007;282:6380-7.

36. Mukoyama Y, Utani A, Matsui S, Zhou S, Miyachi Y, Matsuyoshi N. T-cadherin enhances cell-matrix adhesiveness by regulating beta1 integrin trafficking in cutaneous squamous carcinoma cells. Genes Cells. 2007;12:787-96.

37. Han X, Guo B, Li Y, Zhu B. Tissue factor in tumor microenvironment: a systematic review. J Hematol Oncol. 2014;7:54.

38. Onodera Y, Nam JM, Sabe H. Intracellular trafficking of integrins in cancer cells. Pharmacol Ther. 2013;140:1-9.

39. Wang Y, Arjonen A, Pouwels J, Ta H, Pausch P, Bange G, et al. Formin-like 2 promotes beta1-integrin trafficking and invasive motility downstream of PKCalpha. Dev Cell. 2015;34:475-83.

Ready to submit your research? Choose BMC and benefit from:

- fast, convenient online submission

- thorough peer review by experienced researchers in your field

- rapid publication on acceptance

- support for research data, including large and complex data types

- gold Open Access which fosters wider collaboration and increased citations

- maximum visibility for your research: over 100M website views per year

At BMC, research is always in progress.

Learn more biomedcentral.com/submissions 